\title{
A Systematic Review of Functioning in Vocational Rehabilitation Using the International Classification of Functioning, Disability and Health
}

\author{
Reuben Escorpizo $\cdot$ Monika E. Finger • \\ Andrea Glässel • Felix Gradinger • \\ Miriam Lückenkemper · Alarcos Cieza
}

Published online: 17 February 2011

(C) Springer Science+Business Media, LLC 2011

\begin{abstract}
Background: Vocational rehabilitation (VR) is aimed at engaging or re-engaging individuals with work participation and employment. The International Classification of Functioning, Disability and Health (ICF) by the World Health Organization can be operationalized in the context of VR. The objective of this study is to review the literature to identify outcomes or measures being used in VR using a systematic review methodology and link those measures to the ICF. Methods: We applied a structured search strategy using multiple databases. Items or constructs of the measures or outcomes identified were linked to the ICF by two trained individuals. Results: We have identified 648 measures which contained 10,582
\end{abstract}

R. Escorpizo $(\varangle) \cdot$ M. E. Finger · A. Glässel · F. Gradinger ·

M. Lückenkemper · A. Cieza

Swiss Paraplegic Research (SPF), Guido A. Zäch Str. 4,

6207 Nottwil, Switzerland

e-mail: reuben.escorpizo@paranet.ch

R. Escorpizo · M. E. Finger · A. Glässel · F. Gradinger ·

M. Lückenkemper · A. Cieza

ICF Research Branch in cooperation with the WHO

Collaborating Centre for the Family of International

Classifications in Germany (at DIMDI), Nottwil,

Switzerland

M. E. Finger

Rehaklinik Bellikon, Bellikon, Switzerland

A. Cieza

Institute for Health and Rehabilitation Sciences,

Research Unit for Biopsychosocial Health,

Ludwig-Maximilians Universität, Munich, Germany

R. Escorpizo

Department of Health Sciences and Health Policy, University

of Lucerne, Lucerne, Switzerland concepts that were linked to the ICF which resulted in 87 second-level ICF categories. Out of the 87 categories, 31 (35.6\%) were related to body functions, 43 (49.4\%) were related to activities and participation, and 13 (14.9\%) were related to environmental factors. No category was related to body structures. Conclusions: Our review found great diversity in the ICF contents of the measures used in different VR settings and study populations, which indicates the complexity of VR. This systematic review has provided a list of ICF categories which could be considered towards a successful VR.

Keywords ICF - Vocational rehabilitation - Review · Work · Employment · Outcomes assessment

\section{Introduction}

Work disability (WD) may occur as a result of a health condition or a health-related event and may affect the worker at the individual level and society level. WD may be associated with limited or restricted work participation leading to a decrease in gainful employment and significant burden. Vocational rehab (VR) is a key process in WD management to engage or re-engage individuals with their work participation and employment. VR has been documented in the literature to be effective in addressing the negative consequences of WD [1-6].

The International Classification of Functioning, Disability and Health (ICF) [7] is a universal conceptual framework and classification system by the World Health Organization which has been used to interface with VR or return-to-work, or work participation [8-10]. As a conceptual model, the ICF recognizes that functioning and disability is a result of the interaction between components: 
body functions (b), body structures (s), activities and participation (d), environmental factors (e), and personal factors (not coded). As a classification system, the ICF provides alphanumeric codes that are arranged in a hierarchical fashion, hence different levels, for each of the ICF categories or functioning domains. Below is an illustration of this categorization:

$\begin{array}{ll}\text { ICF component } & \mathrm{d} \text { Activities and participation } \\ \text { Chapter } & \mathrm{d} 4 \text { Mobility } \\ \text { Second-level category } & \mathrm{d} 430 \text { Lifting and carrying objects } \\ \text { Third-level category } & \mathrm{d} 4300 \text { Lifting }\end{array}$

The ICF is a generic framework and intended by the WHO to understand health and functioning, to provide a common language of health and health-related states, to allow comparison between countries and health services, and to provide a uniform coding system regardless of the application setting [7]. However, there remains a lack of understanding of functioning within VR in terms of the ICF. Therefore, the objective of this study is to review the literature to identify outcomes or measures being used in VR using a systematic review methodology. The specific aims of this study are (1) to identify patientreported and clinician-reported outcomes in VR studies and, (2) to identify what aspects of functioning, in the ICF language, were frequently addressed in those outcomes.

\section{Materials and Methods}

\section{Search Strategy}

We applied our search strategy using multiple databases which included Cumulative Index to Nursing and Allied Health Literature $\left(\right.$ CINAHL $\left.^{\circledR}\right)$, PsycINFO ${ }^{\circledR}$, Medline, Global Health, and Vocation and Career Collection. The search strategy included key words and search terms with the Boolean operator "OR": "Vocational rehabilitation", "Return to work", "Occupational rehab*", "Work rehab*", "Work reintegration", "Job rehab*", "Job reentry", "Employ* rehab*", "Employ* reentry". Additional references [11, 12] on a similar research question on VR were consulted.

Studies included were in English, have been conducted using human population or subjects, studies on "vocational or work or occupational rehabilitation" settings, with a study population of working age ( $\geq 18$ years), and published between January 2004 to December 2008. Study designs may be randomized controlled trials (RCT), clinical controlled trials (CCT), cross-sectional studies, longitudinal observational studies, qualitative studies, and case reports. Studies were excluded if they were not specific to vocational rehabilitation, conducted on or with non-human population, were genetic studies or laboratory studies, or were phase I or II clinical trials.

\section{Articles Processing}

Results from our search were exported to a reference system (EndNote ${ }^{\circledR}$ Windows Version X3, Copyright (C) 2009 Thomson Reuters) where possible duplicates were identified. Screening of abstracts and subsequently of full text articles were performed using Microsoft $^{\circledR}$ Access 2007 (Microsoft Corporation, Redmond WA). Abstract screening was independently performed by two trained researchers with the project. All abstracts that were identified were screened and inclusion-exclusion criteria applied. If there was a disagreement on the inclusion or exclusion of articles, then the two individuals met and attempted to resolve the disagreement but if it was not resolved, a third person was asked. Full text articles for the included abstracts were retrieved. The order of full text articles was randomized by the computer from which the first $50 \%$ were selected to build the articles for screening by one screener (S1) and the remaining articles by another screener (S2). Twenty percent of each screener's list of articles was randomly selected for cross-screening (i.e. $20 \%$ of articles of $\mathrm{S} 1$ will be reviewed by $\mathrm{S} 2$ and same amount of S2 by S1). If there was a disagreement on the inclusion-exclusion of the full text articles, then the two screeners met and tried to resolve disagreement. Otherwise, a third person was asked.

\section{Data Extraction}

Based on the finally included articles, the following information, when available, were extracted: country of the first author, the type of study, whether it is a qualitative study or not, whether it is a longitudinal study or not, the type of job and type of VR where the study was conducted, the study setting, and the health condition of the study population. Also extracted were information relating to sociodemographics and standard and non-standard patientreported measures and clinician-reported measures. Standard measures may include questionnaires such as the Medical Outcomes Study Short Form Health Survey-36 items (SF-36) [13] or instrumentation/procedures that are "standardized" such as blood pressure measurement. We did not examine the psychometric properties of the measures identified but they had to be available in English.

\section{Linking to the ICF}

Items or constructs of the measures or outcomes identified were linked to the ICF using published linking rules [14]. 
The objective of the linking process is to be able to translate the concepts found in those items or constructs into the ICF categories. Two independent researchers, who were trained and experienced in the process, linked the responses. Twenty-five percent of the total number of measures were randomly selected and counter-linked by the two researchers. If there was a disagreement between the two, both tried to resolve the disagreement, otherwise a third person was consulted. As a result of the linking process, ICF categories were identified at the second level (common, mid-level way of reporting ICF categories) and a frequency analysis of the common ICF categories was made. Those ICF categories that have been included in at least $5 \%$ of the measures were included in the table.

\section{Reliability of Linking}

To evaluate the reliability of the linking process, the overall percentage of agreement for each questionnaire was calculated based on the two independent linkage versions (at the second-level and third-level of the ICF categories). In addition, to examine the extent to which the achieved agreement exceeds chance, the Kappa coefficient [15] and nonparametric bootstrapped confidence interval [16, 17] were calculated. We performed Kappa analysis using SAS software version 9.1 (Copyright (C) 2002-2003 by SAS Institute Inc., Cary, NC, USA).

\section{Results}

\section{Literature Search}

Our search strategy identified 2997 abstracts and out of which, 334 were subjected to full text screening (i.e. their full text were retrieved). The required information was extracted from 250 articles including study characteristics, VR setting, study population, and characteristics of the measures contained in the studies (Fig. 1).

\section{Study Characteristics}

Based on the first author of the final articles we surveyed $(\mathrm{N}=250)$, most came from the United States (USA) (46.0\%), followed by Canada (10.4\%), and the Netherlands and Sweden (both with 6.8\%). Close to a third of the studies were intervention studies (RCT, CCT, or other type of intervention design). Twenty-six percent of the studies were observational in nature (longitudinal or cross-sectional). Least represented were case studies. While only $10.8 \%$ of the studies surveyed were qualitative, longitudinal studies comprised $52.8 \%$ of the studies. We found a wide range of type of jobs (from service, professional,

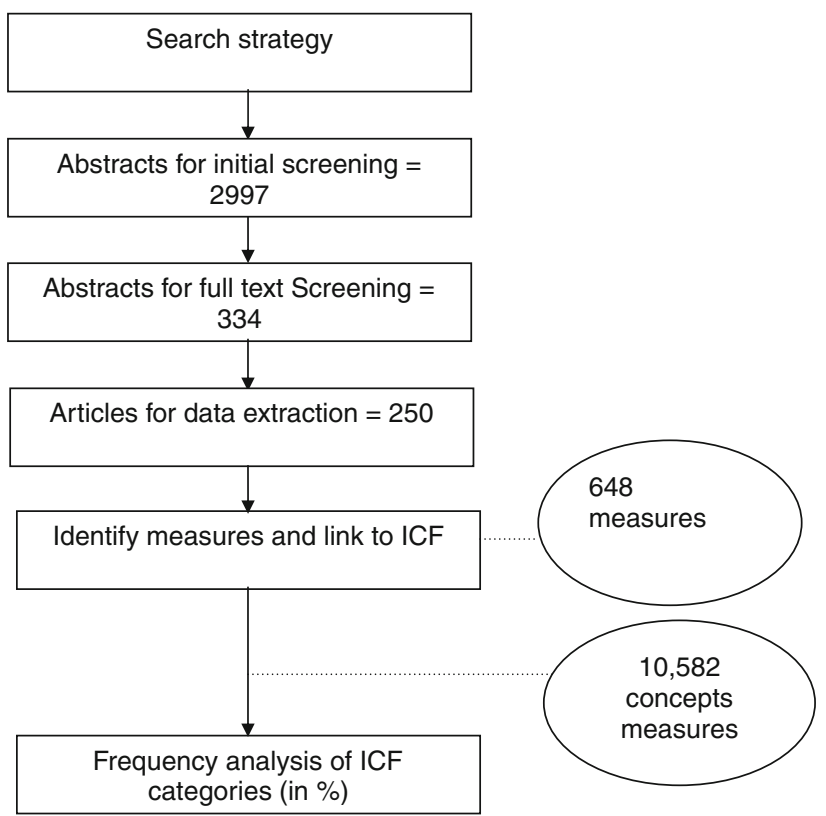

Fig. 1 Search strategy and articles processing flow

administration, technical, to self-employed), study population (with mental, musculoskeletal, and neurologic health conditions), and study settings (outpatient, supported employment, community rehabilitation). Close to $8 \%$ of the studies did not specify the VR setting. Specifically, about $17 \%$ of those studies where settings were specified applied to outpatient facilities or clinics and the least represented was community-based rehabilitation setting (5.6\%). Mental health conditions such as depression comprised the majority $(45.2 \%)$ of the study population and with musculoskeletal conditions such as back pain following second $(33.2 \%)$ (Table 1). Some studies did not specify their study population (6.8\%).

\section{Overview of Measures}

As shown in Fig. 1, we have identified a total of 648 measures. Of these measures, there were 155 questionnaires or clinical tests, 121 one-item measures (e.g. pain, employment arrangement, etc.), and 371 "other" measures. Table 2 provides a list of measures that were used in the studies we found. We only included those which have been used in at least five studies.

Included in Table 2 are the number of times a measure has been used and a short description of the measure. There were 11 self-reported or patient-reported measures with the Medical Outcomes Study 36-item Short Form (SF-36) [13] being the most frequently used (21) and there were 8 provider-reported or third-party reported measures with the Positive and Negative Syndrome Scale (PANSS) [49] with the most frequently used (28). We also extracted 
Table 1 Study characteristics

\begin{tabular}{|c|c|}
\hline \multirow[t]{7}{*}{ Country $(<3 \%$ not included here $)$} & USA $(46 \%)$ \\
\hline & Canada $(10.4 \%)$ \\
\hline & Netherlands $(6.8 \%)$ \\
\hline & Sweden $(6.8 \%)$ \\
\hline & Hong Kong (5.2\%) \\
\hline & United Kingdom (4.4\%) \\
\hline & Australia $(3.2 \%)$ \\
\hline \multirow[t]{8}{*}{ Study type $(<3 \%$ not included here $)$} & Intervention study (RCT) (22\%) \\
\hline & Observational study (longitudinal) $(17.2 \%)$ \\
\hline & Observational study (cross-sectional) $(8.8 \%)$ \\
\hline & Intervention study (CCT) (7.2\%) \\
\hline & Retrospective chart review (4.4\%) \\
\hline & Data analysis (4\%) \\
\hline & Intervention study (other) (3.6\%) \\
\hline & Case study $(3.2 \%)$ \\
\hline Qualitative study & $10.8 \%$ \\
\hline Longitudinal study & $52.8 \%$ \\
\hline \multirow{5}{*}{$\begin{array}{l}\text { Type of job (as worded and specified } \\
\text { by the study) }\end{array}$} & Service \\
\hline & Professional \\
\hline & Administration \\
\hline & Technical \\
\hline & Self-employed \\
\hline \multirow{4}{*}{$\begin{array}{l}\text { Study setting (as worded } \\
\text { and specified by the study) } \\
\text { (<3\% not included here) }\end{array}$} & Outpatient $(16.8 \%)$ \\
\hline & $\begin{array}{l}\text { Supported employment/Individual } \\
\text { support and employment }(14.4 \%)\end{array}$ \\
\hline & Setting not specified $(7.6 \%)$ \\
\hline & Community rehabilitation $(5.6 \%)$ \\
\hline \multirow[t]{5}{*}{ Health condition $(<3 \%$ not included here $)$} & Mental (e.g. bipolar disorders, depression) $(45.2 \%)$ \\
\hline & Musculoskeletal (e.g. back pain) (33.2\%) \\
\hline & Other $(24.8 \%)$ \\
\hline & Neurologic (e.g. stroke, brain injury) (12.4\%) \\
\hline & Condition not specified (6.8\%) \\
\hline
\end{tabular}

$R C T$ randomized controlled trials, $C C T$ controlled clinical trials body structures, 43 (49.4\%) were related to activities and participation (Table 4), and $13(14.9 \%)$ were related to environmental factors (Table 5).

Our reliability calculation between linkers (researchers) at the second-level ICF categories resulted in an overall percentage agreement of $73.4 \%$, an estimated 0.72 Kappa coefficient, and a confidence interval (bias corrected percentile method) of $0.70-0.74$. For the third-level categories, the overall percentage agreement was $69.7 \%$, estimated 0.68 Kappa coefficient, and a confidence interval (bias corrected percentile method) of $0.66-0.70$.

\section{Discussion}

VR is a key enabling process in work disability management. VR as a complex process aimed towards engaging or re-engaging people in gainful employment covers a wide variety of factors. Based on our findings, we found VR to 
Table 2 Measures which have been used in at least 5 studies reviewed in vocational rehabilitation

\begin{tabular}{lll}
\hline Name of measure & Number of & Brief description of measure/sample items \\
& citations where \\
& measure was \\
& used
\end{tabular}

Standard self-reported or patient-reported measures

Medical Outcomes Study 36-item Short 21

Form (SF-36) [13]

Beck Depression Inventory II [29] 9

Tampa Scale for Kinesiophobia [32] 9

Roland-Morris Disability Questionnaire 8 [36]

Pain Disability Index [33]

6

Fear-avoidance Belief Questionnaire [37] 5

Hospital Anxiety and Depression Scale 5

(HADS) [50]

McGill Pain Questionnaire (Pain Rating 5

Index) [34]

Oswestry Low Back Pain Disability 5

Questionnaire (ODQ) [38]

Pain Catastrophizing Scale [35]

WHO Quality of Life Measure (WHO-

QOL) [31]

Standard Provider-reported or Third-party reported measures

Positive and Negative Syndrome Scale 28

(PANSS) [49]

Wisconsin Card Sorting Test [51]

Joint range of motion (ROM)

Strength 9

Trail Marking Test [52] 9

Brief psychiatric rating scale (BPRS) [30] 6

Gorham's Proverbs Test [53] 6

Global Assessment of Functioning Scale 5

(GAF) Part of DSM-IV [54]

Nonstandard measures

Work status

Work participation

Work intervention
Generic measure of limitations in physical activities because of health problems, limitations in social activities because of physical or emotional problems, limitations in usual role activities because of physical health or emotional problems, bodily pain, general mental health (psychological distress and wellbeing), vitality (energy and fatigue), and general health perceptions

Assesses the severity of depression (i.e. symptom of depression)

Assesses fear of movement/(re)injury in individuals with pain

Assesses difficulty or limitation with activities due to low back pain

Measures the impact that pain has on the ability of a person to participate in essential life activities

Measures how much fear and avoidance are affecting a patient with low back pain

Instrument for anxiety and depression in patients with both somatic and mental problems

Measures three dimensions of pain experience: the sensory, the affective and the evaluative dimensions of pain

Assesses pain-related disability in persons with low back pain, assess patients with low back pain by determining its impact on the activities of daily living

Measures "catastrophizing" of pain- which is hypothesized to be related to various levels of pain, physical disability and psychological disability

Assesses quality of life and the individual's perceptions in the context of their culture and value systems, and their personal goals, standards and concerns

Psychiatric measure of positive and negative symptoms and gauges their relationship to one another and to global psychopathology

Allows the clinician to assess the following "frontal" lobe functions: strategic planning, organized searching, utilizing environmental feedback to shift cognitive sets, directing behaviour toward achieving a goal, and modulating impulsive responding

Sample operationalization: ROM of cervical spine

Sample operationalization: grip strength

Neuropsychological test of visual attention and task switching

Assesses the level of symptom constructs such as hostility, suspiciousness, hallucination, and grandiosity

A test for the study of intellectual functioning; measurement of verbal comprehension

Rates the social, occupational, and psychological functioning of adults, e.g. how well or adaptively one is meeting various problems-in-living

Are you working at the time of data collection (admission and discharge)?

Do you expect to be able to resume work (full time or part time)?

Stable employment, improved employment, or unstable employment?

Do you expect difficulties in returning to or staying in gainful employment because of your current health situation?

Job tenure- total duration of continuous employment over 12 months

Work adjustment (carrying out duty and responsibility)

What types or VR services have you received?

What were the strengths (or positives) of the VR program? 
Table 2 continued

\begin{tabular}{|c|c|c|}
\hline Name of measure & $\begin{array}{l}\text { Number of } \\
\text { citations where } \\
\text { measure was } \\
\text { used }\end{array}$ & Brief description of measure/sample items \\
\hline Pain & 47 & $\begin{array}{l}\text { Length of pain duration } \\
\text { Pain radiation in both legs? } \\
\text { Pain diary } \\
\text { Perceived pain intensity }\end{array}$ \\
\hline Work hours & 34 & $\begin{array}{l}\text { Average number of hourse worked } \\
\text { Number of full time employee hours }\end{array}$ \\
\hline Workplace & 29 & $\begin{array}{l}\text { Did anyone from your workplace contact you after your injury (excluding } \\
\text { co-workers)? } \\
\text { Company provides guidance for new workers } \\
\text { Support provided by supervisors or managers }\end{array}$ \\
\hline Cost & 21 & $\begin{array}{l}\text { Case expenditures } \\
\text { Health care cost } \\
\text { Dollar value of provider payments }\end{array}$ \\
\hline Income & 21 & Salary \\
\hline Time of injury, intervention, and RTW & 19 & $\begin{array}{l}\text { Time from onset of injury to program admission } \\
\text { Time from referral to outcome of claimants } \\
\text { Time to job placement }\end{array}$ \\
\hline Satisfaction & 18 & $\begin{array}{l}\text { Satisfaction with current job } \\
\text { Satisfaction with treatment } \\
\text { Satisfaction: clinician explained what to expect, concern for safety, and } \\
\text { confidence in staff skills }\end{array}$ \\
\hline Sick leave & 18 & $\begin{array}{l}\text { Sickness absence in days } \\
\text { Time off work }\end{array}$ \\
\hline Diagnosis & 17 & $\begin{array}{l}\text { Diagnostic tests (e.g. CT scan) } \\
\text { Pre-injury chronic health problems }\end{array}$ \\
\hline Medication & 13 & $\begin{array}{l}\text { Are you currently taking psychiatric medication? } \\
\text { When you take your medication, how much do you take? }\end{array}$ \\
\hline Work ability/capacity & 13 & $\begin{array}{l}\text { To what degree is your ability to perform your ordinary work reduced today? } \\
\text { Ability to work in } \% \text { of a full time job } \\
\text { Maximal lifting capacity }\end{array}$ \\
\hline Benefits & 12 & $\begin{array}{l}\text { Amount of sickness allowance } \\
\text { Disability pension }\end{array}$ \\
\hline Physical capacity & 11 & $\begin{array}{l}\text { Sit to stand test- number of sit to stands in one min } \\
\text { Strength of the trunk flexors/extensors via isokinetic test }\end{array}$ \\
\hline Intervention outcome & 10 & $\begin{array}{l}\text { Dropout from care } \\
\text { After VR: working, studying, unemployed but with working capacity, or further } \\
\text { rehabilitation or assessment }\end{array}$ \\
\hline Work demands & 10 & $\begin{array}{l}\text { How often do you sit continuously for more than } 1 \mathrm{~h} \text { without any standing or } \\
\text { walking? } \\
\text { Exposure to vibration }\end{array}$ \\
\hline Substance abuse & 8 & $\begin{array}{l}\text { Substance abuse history } \\
\text { Drug test }\end{array}$ \\
\hline Work type & 8 & Characteristics of job \\
\hline Employment rate & 7 & Unemployment level in percentage \\
\hline Healthcare provider (HCP) & 7 & $\begin{array}{l}\text { Number of visits to new healthcare providers } \\
\text { Your HCP made contact with your employer? }\end{array}$ \\
\hline
\end{tabular}


Table 2 continued

\begin{tabular}{|c|c|c|}
\hline Name of measure & $\begin{array}{l}\text { Number of } \\
\text { citations where } \\
\text { measure was } \\
\text { used }\end{array}$ & Brief description of measure/sample items \\
\hline Brakes & 6 & $\begin{array}{l}\text { How often do you have short breaks during your computer work? } \\
\text { Do you have exercise breaks at work? }\end{array}$ \\
\hline Hospitalization & 6 & $\begin{array}{l}\text { Number of hospitalization days } \\
\text { Age during first hospitalization }\end{array}$ \\
\hline Body Mass Index & 5 & Height and body weight \\
\hline Physical examination & 5 & Clinical examination \\
\hline Staff & 5 & $\begin{array}{l}\text { Staff accountable for transition to competitive employment } \\
\text { Staff perception of factors that positively and negatively affected program } \\
\text { performance }\end{array}$ \\
\hline Walk & 5 & Ability to walk \\
\hline Work accommodation & 5 & $\begin{array}{l}\text { Did you accept the work accommodation offer? } \\
\text { Presence of material/immaterial adaptations at work }\end{array}$ \\
\hline Work limitation & 5 & $\begin{array}{l}\text { Experience of job-related barriers and successes } \\
\text { Work difficulties during employment }\end{array}$ \\
\hline
\end{tabular}

Table 3 ICF component of body functions $(N=31)$ (categories with $<5 \%$ representation not included)

\begin{tabular}{|c|c|c|}
\hline ICF Code & Title & Percentage $(\%)$ \\
\hline b152 & Emotional functions & 48 \\
\hline b130 & Energy and drive functions & 42 \\
\hline b126 & Temperament and personality functions & 39 \\
\hline b160 & Thought functions & 32 \\
\hline b280 & Sensation of pain & 32 \\
\hline b164 & Higher-level cognitive functions & 27 \\
\hline b140 & Attention functions & 26 \\
\hline b180 & Experience of self and time functions & 25 \\
\hline b134 & Sleep functions & 23 \\
\hline b147 & Psychomotor functions & 23 \\
\hline b156 & Perceptual functions & 20 \\
\hline b765 & Involuntary movement functions & 20 \\
\hline b110 & Consciousness functions & 18 \\
\hline b114 & Orientation functions & 18 \\
\hline b167 & Mental functions of language & 17 \\
\hline b830 & Other functions of the skin & 17 \\
\hline b780 & Sensations related to muscles and movement functions & 16 \\
\hline b270 & Sensory functions related to temperature and other stimuli & 14 \\
\hline b735 & Muscle tone functions & 12 \\
\hline b730 & Muscle power functions & 11 \\
\hline b144 & Memory functions & 8 \\
\hline b440 & Respiration functions & 8 \\
\hline b117 & Intellectual functions & 7 \\
\hline b289 & Sensation of pain, other specified and unspecified & 7 \\
\hline b455 & Exercise tolerance functions & 7 \\
\hline b530 & Weight maintenance functions & 7 \\
\hline b410 & Heart functions & 6 \\
\hline
\end{tabular}


Table 3 continued

\begin{tabular}{lll}
\hline ICF Code & Title & Percentage (\%) \\
\hline b535 & Sensations associated with the digestive system & 6 \\
b760 & Control of voluntary movement functions & 6 \\
b240 & Sensations associated with hearing and vestibular functions & 5 \\
b460 & Sensations associated with cardiovascular and respiratory functions & 5 \\
\hline
\end{tabular}

Table 4 ICF component of activities and participation $(N=43)$ (categories with $<5 \%$ representation not included)

\begin{tabular}{|c|c|c|}
\hline ICF code & Title & Percentage $(\%)$ \\
\hline d850 & Remunerative employment & 71 \\
\hline d920 & Recreation and leisure & 31 \\
\hline d540 & Dressing & 23 \\
\hline d855 & Non-remunerative employment & 23 \\
\hline $\mathrm{d} 450$ & Walking & 22 \\
\hline d177 & Making decisions & 21 \\
\hline $\mathrm{d} 230$ & Carrying out daily routine & 21 \\
\hline $\mathrm{d} 410$ & Changing basic body position & 21 \\
\hline $\mathrm{d} 455$ & Moving around & 20 \\
\hline d845 & Acquiring, keeping and terminating a job & 19 \\
\hline $\mathrm{d} 430$ & Lifting and carrying objects & 18 \\
\hline d510 & Washing oneself & 18 \\
\hline d760 & Family relationships & 18 \\
\hline d 350 & Conversation & 17 \\
\hline d720 & Complex interpersonal interactions & 17 \\
\hline d750 & Informal social relationships & 17 \\
\hline d640 & Doing housework & 16 \\
\hline d710 & Basic interpersonal interactions & 16 \\
\hline d770 & Intimate relationships & 15 \\
\hline d445 & Hand and arm use & 14 \\
\hline d570 & Looking after one's health & 14 \\
\hline d160 & Focusing attention & 12 \\
\hline $\mathrm{d} 315$ & Communicating with- receiving- nonverbal messages & 12 \\
\hline d335 & Producing nonverbal messages & 12 \\
\hline d859 & Work and employment, other specified and unspecified & 10 \\
\hline d415 & Maintaining a body position & 9 \\
\hline $\mathrm{d} 475$ & Driving & 9 \\
\hline d650 & Caring for household objects & 8 \\
\hline d825 & Vocational training & 8 \\
\hline $\mathrm{d} 220$ & Undertaking multiple tasks & 7 \\
\hline $\mathrm{d} 470$ & Using transportation & 7 \\
\hline d550 & Eating & 7 \\
\hline d620 & Acquisition of goods and services & 7 \\
\hline d820 & School education & 7 \\
\hline d830 & Higher education & 7 \\
\hline d440 & Fine hand use & 6 \\
\hline d498 & Mobility, other specified & 6 \\
\hline d660 & Assisting others & 6 \\
\hline $\mathrm{d} 870$ & Economic self-sufficiency & 6 \\
\hline d175 & Solving problems & 5 \\
\hline $\mathrm{d} 210$ & Undertaking a single task & 5 \\
\hline
\end{tabular}


Table 4 continued

\begin{tabular}{lll}
\hline ICF code & Title & Percentage $(\%)$ \\
\hline d240 & Handling stress and other psychological demands & 5 \\
d420 & Transferring oneself & 5 \\
\hline
\end{tabular}

Table 5 ICF component of environmental factors $(N=13)$ (categories with $<5 \%$ representation not included)

\begin{tabular}{lll}
\hline ICF code & Title & Percentage (\%) \\
\hline e580 & Health services, systems and policies & 33 \\
e590 & Labour and employment services, systems and policies & 28 \\
e310 & Immediate family & 21 \\
e355 & Health professionals & 21 \\
e165 & Assets & 20 \\
e110 & Products or substances for personal consumption & 19 \\
e570 & Social security services, systems and policies & 10 \\
e320 & Friends & 9 \\
e330 & People in positions of authority & 9 \\
e315 & Extended family & 8 \\
e540 & Transportation services, systems and policies & 8 \\
e325 & Acquaintances, peers, colleagues, neighbors and community members & 7 \\
e155 & Design, construction and building products and technology of buildings & 5 \\
& for private use & \\
\hline
\end{tabular}

operate in diverse health-condition and service provisiontype setting, research study design, and job types. This diversity is likely to be indicative of the array of measures being used. We also found that VR is reported in the literature mostly from developed countries. Using the ICF by the WHO offers us a generic framework so as to understand VR's multitude of factors and players with the benefits of the ICF's common language and cross-setting and multi-cultural application. We investigated measures that were reported in the literature through a systematic review and linked those measures to the ICF. In that way, outcomes or simply variables can be interpreted to be meaningful to ICF users. The ICF contents of the measures we found in the literature reflect the breadth of VR as a field of research and practice.

Knowledge of the factors we found would be helpful to inform appropriate intervention and care in facilitating optimal VR, and hence work participation. The factors in the ICF language provide us with a uniform language of functioning and disability that is in line with WHO. We believe that this study would contribute to improve outcomes measurement in VR.

Systematic reviews do give us a rich source of information on the state of a research agenda which look into the applicability of the findings to the field as a whole or to a subset of the field [18, 19]. Similarly, information gathered from synthesizing the literature provides a comprehensive and rich source of understanding workers with disability in terms of what measures or outcomes are available out there and how we can make use of them effectively.

Our review showed that most of the studies originated or were conducted in the developed countries such as the USA, Canada, and European countries. This observation implies that literature in VR is skewed towards countries that have VR infrastructure in place. VR services and how they are being delivered even differ between developed countries [20, 21] due to systems difference. Personal factors and attitudinal factors and diverse sociodemographics may influence VR outcomes in one part of the world to a different degree [22]. However, it could also be possible that since the articles need to be in English to qualify for our screening, we got articles from countries that do speak English.

In VR, where outcomes could fluctuate from being off from work to being back to work full-time to part-time, it is essential to capture these processes over time. Indeed, this temporal component of VR was indicated by about half of the studies for which there was information available, were longitudinal studies. However, this was not the case with qualitative studies as it only constituted a mere tenth of the studies, despite the continuing support for using qualitative methodology in addressing WD issues [23, 24]. Our findings also revealed that VR does cover a variety of jobs (physical demands, mental demands, or a combination of both) and can be implemented in different health care 
settings (outpatient, inpatient, supported employment) although the latter observation may depend on what is allowed by the system of that country within a particular state of work disability (i.e. eligibility for VR services over time). Health conditions were mostly mental and musculoskeletal in nature. This finding is indicative of the prevalence and burden that both groups of health conditions (alone or in coexistence) pose [25-28].

The type of measures we found varied which was an expected finding to reflect the spectrum of health conditions in VR. We can say that the type of measure used in a study is driven by the type of population being investigated. For example, most of studies dealt with mental health and hence, the Positive and Negative Syndrome Scale (PANSS) [49] and Beck Depression Inventory II (BDI) [29] were commonly used and both are psychological-psychiatric measures. A look at the measures that were used in at least 5 studies revealed a diverse list. Different domains and constructs were covered in mental health such as the Beck Depression Inventory (BDI) [29] and the Brief Psychiatric Rating Scale (BPRS) [30] to quality of life such as the WHO Quality of Life measure (WHO-QOL) [31]- this finding reflects the many health conditions that fall under VR. The popular Medical Outcomes Study Short Form 36-items (SF-36) [13] was the most commonly used generic self-report measure but many measures were also intended to capture "pain" and the surrounding factors around it [32-35]. More specifically, back pain as a health condition, is central to some of these measures such as the Roland-Morris Disability Questionnaire (RMDQ) [36], Fear-avoidance Belief Questionnaire (FABQ) [37], and the Oswestry Low Back Pain Disability Questionnaire (OLBPQ) [38]. Some measures were patient-reported and others clinician-reported or third-party reported (e.g. caregiver, family). We decided a priori to take both types of measures so as to give us a comprehensive picture of what is being reflected in the general world of measures used in VR.

There were more nonstandard measures (i.e. no uniform way of gathering the information) than standard measures like those stated earlier. This is particularly interesting because the standard measures while widely used in VR, are not necessarily specific to "work" or are not enough to capture VR and work disability as a process. Therefore, we were not surprised to see a list of specific work-related questions (e.g. work status, level of work participation, work intervention, etc.) which we believe adds value to examining VR outcomes from a comprehensive perspective. Moreover, some of nonstandard items, which we presumed would have had a "standard" definition, were actually defined differently. For example, the item "work status" was not confined to being at work or off-work but was rather operationalized in different ways: "What will be your condition when you return to work or unemployment status?" [39], "Have you resumed your previous job with modifications or changed to a new job?" [40], or "Do you expect to be able to resume work (full time or part time)?" [41]. Despite the relatively high number of measures in VR that we found, only a few of them were used frequently in the literature. The selection of standard measures seem to rely on the type of health condition, while non-standard measures, given that they are a central theme around the area of "work", does not.

This literature study covered three classifiable components of the ICF: body functions, activities and participation, and environmental factors. Of these components, activities and participation had the most categories followed by body functions. The least representation was found for environmental factors. This finding signifies a broad societal perspective rather than a consideration for the individual structure-level alone. It is consistent with findings of relevant ICF components in the mental health field [42] and is also consistent with the conceptualization of work functioning by Sandqvist and Henriksson (2004) which emphasized the role of work participation and performance, individual capacity, and environmental factors [43].

Work resumption or absence from work is commonly used as an indicator of VR success [3, 44-46]. For activities and participation, remunerative or gainful employment was most frequently contained in the measures. Other work-relevant categories were $d 845$ acquiring, keeping and terminating a job, d177 making decisions (perhaps applicable to mental-type of health conditions or jobs that demand mental competency), and 1430 lifting and carrying objects (perhaps applicable to physical-type of health conditions or jobs that demand physical skills), for example. However, the role of traditionally non-work relevant factors such as d855 non-remunerative employment (e.g. volunteer), $d 920$ recreation and leisure, and $d 230$ carrying out daily routine, were evident. These factors point to the multi-faceted dimensions of VR that go beyond the traditional confines- to include what people do outside of their work and how it impacts their ability to return to work or assume work [47]. This also proves that "employment" in a sense, does not have to necessarily be paid to be considered "work".

Surrounding people such as family (e310 immediate family, e315 extended family), friends (e320 friends), and co-workers (e325 acquaintances, peers, colleagues, neighbours and community members) could impact VR outcomes. This finding reinforces the importance of support and relationship as part of one's social environment $[8,46]$. Moreover, the support that comes from health care services and providers (e580 health services, systems and policies and e355 health professionals), labour services and providers (e590 labour and employment services, systems 
and policies), and social security services and providers (e570 social security services, systems and policies) was also evident in the measures surveyed. At a quick glance, these three areas of services on health, labour, and social security seem to the "trifecta" in VR provision. Assets (e165) in the form of money, income, salary, or financial benefit were not unexpected because it could facilitate or sustain return to work [8].

Looking at the body functions categories, it is notable that they are so varied to the effect that they could be applied to a variety of diseases that may either be physical or mental in nature, or both. For example, mental health-related categories include b126 temperament and personality functions and b160 thought functions, while physical health-related categories include b765 involuntary movement functions. This finding may not necessarily be surprising because most of the studies, as previously mentioned, were on mental and musculoskeletal disease settings.

Looking at the different dimensions of functioning we found based on the measures we reviewed, the literature is driven toward activities and participation which is logical because work or employment is a major life area and as such is related to activity and participation. Clearly, the gap is in the area of environmental factors because of its less representation despite its importance in the facilitation work functioning [43]. Looking at each ICF component, a high number of body functions categories related to the chapter on mental functions- a consistent finding since most study populations were on mental health. The distribution was relatively non-pronounced in the other ICF components.

With regards to our linking methodology, there was not only a satisfactory agreement between the linkers but the agreement also exceeded chance. This shows that the linking procedure was reliable in this study.

We do recognize the limitations of our study. First, the results of our systematic review could not be made generalizable if not applicable to all settings of VR. While the review made an attempt to capture the broadest representation of measures used in VR, the review covered a limited period of 5 years. Secondly, not all the studies we included had the information we required. For example, some studies did not specify or were not explicit about the type of job that the VR patients had, or what the specific type of setting it was (outpatient versus inpatient). The nature of the health conditions of the population examined was missing in some studies. Therefore, we only calculated the percentages based on the studies that did provide information which could lead to underestimation. Thirdly, the studies were not evaluated in terms of their quality of evidence. Although this was not the purpose of this review, information on the quality may help in judging whether or not the factors identified in those studies carry scientific robustness [48].
This systematic review has provided us with ICF categories that were considered in the measures used in VR which can help advance our understanding of the factors around successful VR. This study, therefore, provides us with the "what" to measure in the VR based on the systematic review of the literature. Knowing what to measure could better inform us with the challenges ahead when managing patients in VR. Moreover, by identifying the variety of standard and nonstandard measures that were used in the literature further adds to the complexity of "how" to measure or operationalize the ICF categories and creating an outcome measure that will truly reflect the improvement during or after a VR program. This study also proposed a list of variables that would apply to VR programs regardless of the health condition, setting, region, or culture. Looking at the ICF categories, they are truly representative of many settings and are covered to varying extent by the measures we found. Moreover, the findings of this study could also inform us in developing new outcome measures or instruments or validating existing ones.

\section{Conclusions}

We encourage the VR clinical and research community and ICF users to further examine the list of variables as provided in our literature review. Empirical testing will be needed and validation studies are being planned to operationalize the ICF categories amidst the multiple and possibly inter-related variables of VR. The measurement of outcomes in the practice and research of VR is imperative if we want to improve people's lives by increasing their work participation and fulfilling their societal role in general. We believe that this study is one starting point towards advancing measurement in VR.

Acknowledgments The authors would like to thank Dr. Teresa Brinkel, Anne-Katrin Brust, Kathrin Ecker, and Wolfgang Segerer for providing technical consultation and help during the conduct of the study. Special thanks to Cristina Bostan, who is supported by a Marie Curie Fellowship from the EU funded project MURINET, the ICF Research Branch and the Swiss Paraplegic Research in Nottwil, Switzerland. This project was funded by the Swiss Accident Insurance Company (SUVA).

Conflict of interest None.

\section{References}

1. Khan F, Ng L, Turner-Stokes L. Effectiveness of vocational rehabilitation intervention on the return to work and employment of persons with multiple sclerosis. Cochrane Database Syst Rev. 2009;1(1):CD007256.

2. Lysaker PH, Davis LW, Bryson GJ, Bell MD. Effects of cognitive behavioral therapy on work outcomes in vocational 
rehabilitation for participants with schizophrenia spectrum disorders. Schizophr Res. 2009;107(2-3):186-91.

3. Suoyrjo H, Oksanen T, Hinkka K, Kivimaki M, Klaukka T, Pentti $\mathrm{J}$, et al. The effectiveness of vocationally oriented multidisciplinary intervention on sickness absence and early retirement among employees at risk: an observational study. Occup Environ Med. 2009;66(4):235-42.

4. Marini I, Lee GK, Chan F, Chapin MH, Romero MG. Vocational rehabilitation service patterns related to successful competitive employment outcomes of persons with spinal cord injury. J Vocat Rehabil. 2008;28(1):1-13.

5. Dutta A, Gervey R, Chan F, Chou CC, Ditchman N. Vocational rehabilitation services and employment outcomes for people with disabilities: a United States study. J Occup Rehabil. 2008;18(4): 326-34.

6. Crowther R, Marshall M, Bond G, Huxley P. Vocational rehabilitation for people with severe mental illness. Cochrane Database Syst Rev. 2001;2(2):CD003080.

7. World Health Organization. International classification of functioning, disability and health. 2001; WHO, Geneva.

8. Young AE. Return to work following disabling occupational injury-facilitators of employment continuation. Scand J Work Environ Health. 2010;36(6):473-83.

9. Lagerveld SE, Bultmann U, Franche RL, van Dijk FJ, Vlasveld MC, van der Feltz-Cornelis CM, et al. Factors associated with work participation and work functioning in depressed workers: a systematic review. J Occup Rehabil. 2010;20(3):275-92.

10. Homa DB. Using the international classification of functioning, disability and health (ICF) in job placement. Work. 2007;29(4): 277-86.

11. Gehanno JF, Rollin L, Le Jean T, Louvel A, Darmoni S, Shaw W. Precision and recall of search strategies for identifying studies on return-to-work in Medline. J Occup Rehabil. 2009;19(3):223-30.

12. Marshall M, Bond GR, Huxley P. Vocational rehabilitation for people with severe mental illness. Cochrane Database of Systematic Reviews 2001(2. Art. No.: CD003080).

13. Ware JE Jr., Sherbourne CD. The MOS 36-item short-form health survey (SF-36). I. Conceptual framework and item selection. Med Care. 1992;30(6):473-83.

14. Cieza A, Geyh S, Chatterji S, Kostanjsek N, Ustun B, Stucki G. ICF linking rules: an update based on lessons learned. J Rehabil Med. 2005;37(4):212-8

15. Cohen J. A coefficient of agreement for nominal scales. Educ Psychol Meas. 1960;20:37-46.

16. Efron B. The jack nife, the bootstrap and other resampling plans. Philadelphia, PA: Society for industrial and applied mathematics; 1982.

17. Vierkant RA. A SAS macro for calculating bootstrapped confidence intervals about a Kappa coefficient. Available from: http://www2.sas.com/proceedings/sugi22/STATS/PAPER295. PDF.2009.

18. Stevens KR. Systematic reviews: the heart of evidence-based practice. AACN Clin Issues. 2001;12(4):529-38.

19. Mulrow CD. Rationale for systematic reviews. BMJ. 1994;309(6954): 597-9.

20. Stubbs J, Deaner G. When considering vocational rehabilitation: describing and comparing the Swedish and American systems and professions. Work. 2005;24(3):239-49.

21. Muijzer A, Groothoff JW, de Boer WE, Geertzen JH, Brouwer S. The assessment of efforts to return to work in the European Union. Eur J Public Health. 2010.

22. Lee R, Chan C. Factors affecting vocational outcomes of people with chronic illness participating in a supported competitive open employment program in Hong Kong. Work. 2005;25(4):359-68.

23. Buijs PC, Lambeek LC, Koppenrade V, Hooftman WE, Anema JR. Can workers with chronic back pain shift from pain elimination to function restore at work? Qualitative evaluation of an innovative work related multidisciplinary programme. J Back Musculoskelet Rehabil. 2009;22(2):65-73.

24. Dekkers-Sanchez PM, Wind H, Sluiter JK, Frings-Dresen MH. A qualitative study of perpetuating factors for long term sick leave and promoting factors for return to work: chronic work disabled patients in their own words. J Rehabil Med. 2010;42(6):544-52.

25. Patten SB, Williams JV, Wang J. Mental disorders in a population sample with musculoskeletal disorders. BMC Musculoskelet Disord. 2006;7:37.

26. Wang J, Adair CE, Patten SB. Mental health and related disability among workers: a population-based study. Am J Ind Med. 2006; 49(7):514-22.

27. United States Joint and Bone Decade: The Burden of Musculoskeletal Diseases in the United States. Available from: http://www. boneandjointburden.org.2008/.

28. World Health Organization. The burden of musculoskeletal conditions at the start of the new millenium. 2003;WHO Technical Report Series 919.

29. Beck A, Steer R, Brown G. Manual for Beck Depression Inventory-II. 1996.

30. Overall JEG. D.R. Psychiatric Rating Scale (BPRS): recent developments in ascertainment and scaling. Psychopharmacol Bull. 1988;24:97-9.

31. Study protocol for the World Health Organization project to develop a Quality of Life assessment instrument (WHOQOL). Qual Life Res. 1993;2(2):153-9.

32. Kori SH, Miller RP, Todd DD. Kinesiophobia: a new view of chronic pain behaviour. Pain Manage. 1990;3:35-43.

33. Chibnall JT, Tait RC. The Pain Disability Index: factor structure and normative data. Arch Phys Med Rehabil. 1994;75(10):1082-6.

34. Melzack R. The McGill Pain Questionnaire: major properties and scoring methods. Pain. 1975;1:277-99.

35. Michael JL, Sullivan SR, Bishop JP. The pain catastrophizing scale: development and validation. Psychol Assess. 1995;7(4):524-32.

36. Roland MO, Morris RW. A study of the natural history of back pain. Part 1: Development of a reliable and sensitive measure of disability in low back pain. Spine. 1983;(8):141-4.

37. Waddell G, Newton M, Henderson I, Somerville D, Main CJ. A Fear-Avoidance Beliefs Questionnaire (FABQ) and the role of fear-avoidance beliefs in chronic low back pain and disability. Pain. 1993;52(2):157-68.

38. Fairbank JC, Couper J, Davies JB, O'Brien JP. The Oswestry low back pain disability questionnaire. Physiotherapy. 1980;66(8): 271-3.

39. Drews B, Nielsen CV, Rasmussen MS, Hjort J, Bonde JP. Improving motivation and goal setting for return to work in a population on sick leave: a controlled study. Scand J Public Health. 2007;35(1):86-94.

40. Sang LS, Ying Eria LP. Outcome evaluation of work hardening program for manual workers with work-related back injury. Work. 2005;25(4):297-305.

41. Schonherr MC, Groothoff JW, Mulder GA, Schoppen T, Eisma WH. Vocational reintegration following spinal cord injury: expectations, participation and interventions. Spinal Cord. 2004;42(3):177-84.

42. Sanderson K, Nicholson J, Graves N, Tilse E, Oldenburg B. Mental health in the workplace: using the ICF to model the prospective associations between symptoms, activities, participation and environmental factors. Disabil Rehabil. 2008;30(17): 1289-97.

43. Sandqvist JL, Henriksson CM. Work functioning: a conceptual framework. Work. 2004;23(2):147-57.

44. Luk KD, Wan TW, Wong YW, Cheung KM, Chan KY, Cheng $\mathrm{AC}$, et al. A multidisciplinary rehabilitation programme for patients with chronic low back pain: a prospective study. J Orthop Surg. 2010;18(2):131-8. 
45. Bultmann U, Sherson D, Olsen J, Hansen CL, Lund T, Kilsgaard J. Coordinated and tailored work rehabilitation: a randomized controlled trial with economic evaluation undertaken with workers on sick leave due to musculoskeletal disorders. J Occup Rehabil. 2009;19(1):81-93.

46. Brouwer S, Reneman MF, Bultmann U, van der Klink JJ, Groothoff JW. A prospective study of return to work across health conditions: perceived work attitude, self-efficacy and perceived social support. J Occup Rehabil. 2010;20(1):104-12.

47. Kirsh B, Krupa T, Cockburn L, Gewurtz R. A Canadian model of work integration for persons with mental illnesses. Disabil Rehabil. 2010.

48. Sackett DL, Rosenberg WM, Gray JA, Haynes RB, Richardson WS. Evidence based medicine: what it is and what it isn't. Clin Orthop Relat Res. 2007;455:3-5.
49. Kay SR, Fiszbein A, Opler LA. The positive and negative syndrome scale (PANSS) for schizophrenia. Schizophr Bull. 1987; 13(2):261-76.

50. Zigmond AS, Snaith RP. The hospital anxiety and depression scale. Acta Psychiatr Scand. 1983;67(6):361-70.

51. Berg EA. A simple objective technique for measuring flexibility in thinking. J Gen Psychol. 1948;(39):15-22.

52. Reitan RM. Validity of the trail making test as an indicator of organic brain damage. Percept Mot Skills. 1958;8:271-6.

53. Gorham DR. Use of the proverbs test for differentiating schizophrenics from normals. J Consult Psychol. 1956;20(6):435-40.

54. American Psychiatric Association, editor. Diagnostic and statistical manual of mental disorders (4th ed., text rev.);2000. 